\title{
Graphene formation on SiC substrates
}

\author{
B.L. VanMil ${ }^{1, a}$, R.L. Myers-Ward ${ }^{1, b}$, J.L. Tedesco ${ }^{1, c}$, C.R. Eddy, Jr. ${ }^{1, d}$, \\ G.G. Jernigan ${ }^{1, e}$, J.C. Culbertson ${ }^{1, f^{\prime}}$, P.M. Campbell ${ }^{1,9}$, J.M. McCrate ${ }^{1}$, \\ S.A. Kitt ${ }^{1}$ and D.K. Gaskill ${ }^{1, h}$ \\ ${ }^{1}$ Electronics Science and Technology Division, U.S. Naval Research Laboratory, \\ 4555 Overlook Avenue, SW, Washington, DC 20375, U.S.A. \\ avanmil@amethystresearch2.com, ${ }^{b}$ rward@ccs.nrl.navy.mil, ${ }^{\circ}$ tedesco@estd.nrl.navy.mil, \\ deddy@estd.nrl.navy.mil, "glenn.jernigan@nrl.navy.mil, fjim.culbertson@nrl.navy.mil, \\ gpaul.campbell@nrl.navy.mil, hkurt.gaskill@nrl.navy.mil
}

Keywords: graphene, SiC substrates, Si-face, C-face, growth conditions, morphology, Hall measurements, Raman spectroscopy

\begin{abstract}
Graphene layers were created on both $\mathrm{C}$ and Si faces of semi-insulating, on-axis, $4 \mathrm{H}-$ and $6 \mathrm{H}-\mathrm{SiC}$ substrates. The process was performed under high vacuum $\left(<10^{-4} \mathrm{mbar}\right)$ in a commercial chemical vapor deposition $\mathrm{SiC}$ reactor. A method for $\mathrm{H}_{2}$ etching the on-axis substrates was developed to produce surface steps with heights of $0.5 \mathrm{~nm}$ on the Si-face and 1.0 to $1.5 \mathrm{~nm}$ on the $\mathrm{C}$-face for each polytype. A process was developed to form graphene on the substrates immediately after $\mathrm{H}_{2}$ etching and Raman spectroscopy of these samples confirmed the formation of graphene. The morphology of the graphene is described. For both faces, the underlying substrate morphology was significantly modified during graphene formation; surface steps were up to $15 \mathrm{~nm}$ high and the uniform step morphology was sometimes lost. Mobilities and sheet carrier concentrations derived from Hall Effect measurements on large area (16 mm square) and small area ( 2 and $10 \mu \mathrm{m}$ square) samples are presented and shown to compare favorably to recent reports.
\end{abstract}

\section{Introduction}

The predicted and measured properties of graphene have generated interest in making large area samples to test new technological applications. Since Berger et al.'s [1] initial report of graphene formation by the thermal desorption of $\mathrm{Si}$ from $\mathrm{SiC}$, efforts have been underway to use this method to make large area sheets of graphene. Yet, forming large areas of uniform, electronic grade graphene by the thermal desorption process is very challenging. In this work we describe how an Aixtron VP508 SiC chemical vapor deposition (CVD) reactor using the thermal desorption method can form graphene sheets with properties similar to the best reported to-date. A two-step process is described that starts with an in-situ $\mathrm{H}_{2}$ etch preparation of the on-axis (0001) substrate subsequently followed by the formation of graphene; the properties of the graphene are briefly described.

\section{Experimental}

Prior investigations have shown that $\mathrm{SiC}$ decomposes in vacuo at temperatures above $1200^{\circ} \mathrm{C}$ and, other than residual surface $\mathrm{C}$, the major components are gas phase $\mathrm{Si}$ and $\mathrm{Si}_{2} \mathrm{C}$ [2]; the vapor pressure of the former is estimated to be about $10^{-7} \mathrm{mbar}$ initially rising to about $10^{-5}$ mbar at $1500^{\circ} \mathrm{C}$. This suggests that a CVD reactor operating near these pressures could be able to form graphene. Preliminary work in this laboratory demonstrated the $225 \mathrm{~mm}$ diameter process tube of the VP508 reactor can be operated at pressures below $10^{-4} \mathrm{mbar}$ at $1600^{\circ} \mathrm{C}$ using the turbo pump (Pfeiffer TMH 521) in conjunction with intermittent use of a mechanical pump (Pfeiffer Duo 2.5C) to remove $\mathrm{H}_{2}$ from the cell which is not efficiently removed us- 
ing a turbo pump. In addition, the pumping manifold was heated to $c a .50^{\circ} \mathrm{C}$ as an aid to gas desorption. We call this the high vacuum (HV) approach to graphene.
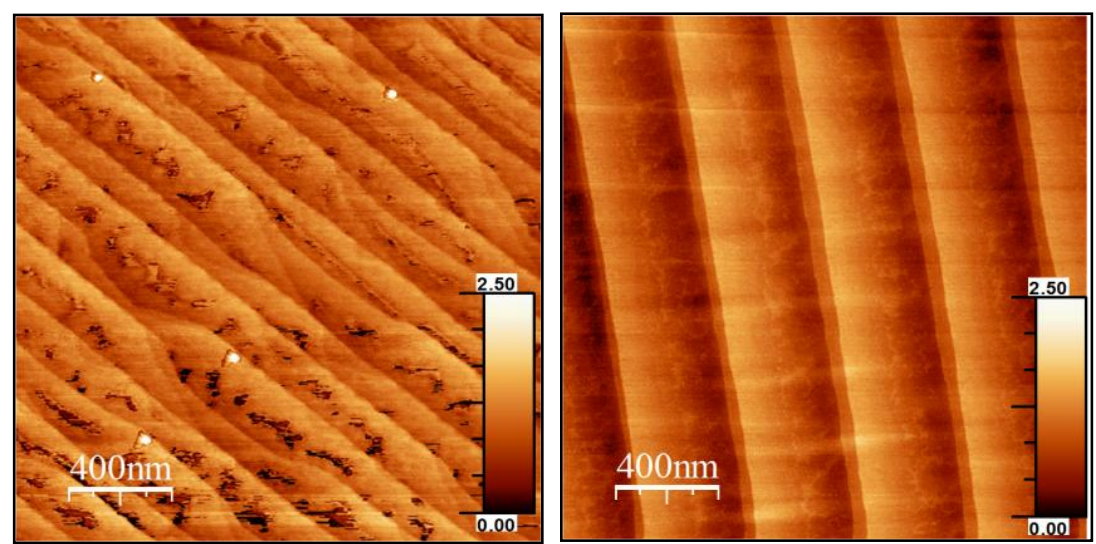

Figure 1. Atomic force map of Si-face (left) and C-face (right) $6 \mathrm{H}$ $\mathrm{SiC}$ after 5 minutes of $\mathrm{H}_{2}$ etching at $1600 \mathrm{C}$. The profile scales (inset) are in nanometers.
Previous $\mathrm{H}_{2}+$ propane etching experiments have been described elsewhere [3] for off-axis substrates and showed the (0001)Si surface was dominated by atomic steps $0.5 \mathrm{~nm}$ high. This work used a similar etching formula for on-axis, semi-insulating substrates; it was found that no propane flow during $\mathrm{H}_{2}$ etching produced the best surfaces. The $\mathrm{H}_{2}$ etching time was about 5 minutes at

$1600^{\circ} \mathrm{C}$ using $50 \mathrm{SLM}$ at a pressure of 100 mbar and some etching occurred during temperature ramp up and down periods; the resulting total etch depth is estimated to be about $300 \mathrm{~nm}$ [4]. Figure 1 shows the atomic force microscopy (AFM - Digital Instruments Nanoscope IIIa, diamond-like carbon-coated tips were used) maps of Si-face and C-face $6 \mathrm{H}-\mathrm{SiC}$ surfaces after $\mathrm{H}_{2}$ etching. The $\mathrm{Si}$-face was dominated by steps $0.50 \mathrm{~nm}$ high on both polytypes whereas for the C-face, steps were $1.0 \mathrm{~nm}(1.0$ to $1.5 \mathrm{~nm})$ high for $4 \mathrm{H}(6 \mathrm{H})$ samples.

Four $16 \mathrm{~mm} \times 16 \mathrm{~mm}$ substrates of on-axis (c-axis misorientation typically $<0.5^{\circ}$ ), semiinsulating $\mathrm{SiC}$ substrates were prepared for each graphene experiment and consisted of both chemo-mechanically polished Si- and C-faces of the $4 \mathrm{H}$ (Cree) and $6 \mathrm{H}$ (II-VI, Inc.) polytypes. These were then $\mathrm{H}_{2}$ etched as described above. To form graphene, two approaches were used. In the first, the $\mathrm{H}_{2}$ flow was ramped to zero while the process tube pressure was lowered to the base pressure ( few mbar) of the process pump (Ebara A25S) and the sample was stabilized at the desired temperature. The process pressure control was then transferred to the turbo pump, and the pressure over the sample was reduced to the range $\leq 0.1$ to $4 \times 10^{-4}$ mbar. These experiments were often limited in duration as the turbo pump could not pump the evolved $\mathrm{H}_{2}$ from the cell and maintain a low pressure. Since process pressure control for the first approach was found to be less than optimal, a second approach was employed that used an Ar flush before graphene formation and the mechanical pump to maintain the pressure below $4 \times 10^{-4}$ mbar. In this approach, after the $\mathrm{H}_{2}$ etch, an Ar flow (15 SLM) replaced the $\mathrm{H}_{2}$ flow and the sample was brought to the desired temperature with the process tube pressure controlled by the process pump base pressure. After temperature stabilization, the process pressure control was transferred to the turbo pump and the pressure of the sample reduced to $\leq 2 \times 10^{-4}$ mbar. If the base pressure exceeded $2 \times 10^{-4}$ mbar, the mechanical pump was added to the pressure control for 2 minute increments until low pressure was again achieved. For both approaches, after the graphene formation step, the sample cooled under turbo pumped vacuum.

Graphene formation was attempted at $1400,1425,1500$, and $1600^{\circ} \mathrm{C}$ for durations of 10 , 60, or 90 minutes. After growth, the samples were characterized by Nomarski microscopy, AFM, scanning electron microscopy (SEM), Raman spectroscopy (532 nm excitation, spot sizes were $50 \mu \mathrm{m}$ and $2 \mu \mathrm{m}$ ) and Hall Effect measurements. Some samples were processed for additional Hall measurements using standard lithographic techniques to form a pattern of 2 and $10 \mu \mathrm{m}$ crosses where the graphene crosses connect to Au contact pads. 


\section{Results and Discussion}

Most samples were probed with Raman spectroscopy and graphene formation was confirmed as the spectra exhibited the distinctive D, G, and 2D Raman lines [5].
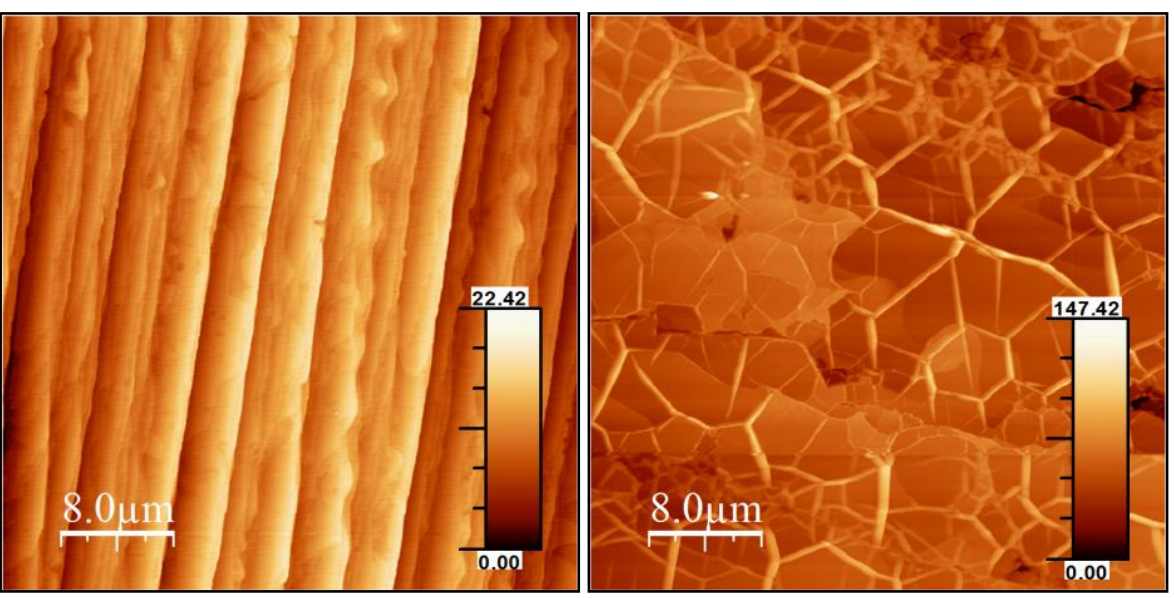

Figure 2. Atomic force map of Si-face (left) and C-face (right) $6 \mathrm{H} \mathrm{SiC} \mathrm{af-}$ ter graphene growth. The profile scales (inset) are in nanometers.
The morphology of graphene on Siface substrates was very different from $\mathrm{C}$ face substrates. Figure 2 shows examples of both morphologies as measured by AFM. Graphene on Si-face, shown in Fig. 2 (left), was rougher than the just etched substrates as shown in Fig. 1(left). No obvious trends with substrate

polytype were discerned. Removal of the graphene by the "Scotch Tape" method demonstrated that the underlying substrate morphology was nearly identical to that of the graphene. This underlying morphology usually showed step bunching with heights ranging from 1 to 15 $\mathrm{nm}$ depending upon growth conditions. In some cases, the steps were no longer regular and appeared to be etched irregularly. Graphene thickness measured by AFM on patterned samples ranged from about 0.5 to $8 \mathrm{~nm}$, depending upon processing conditions. The error in thickness measurements is estimated to be $\sim 1 \mathrm{~nm}$.

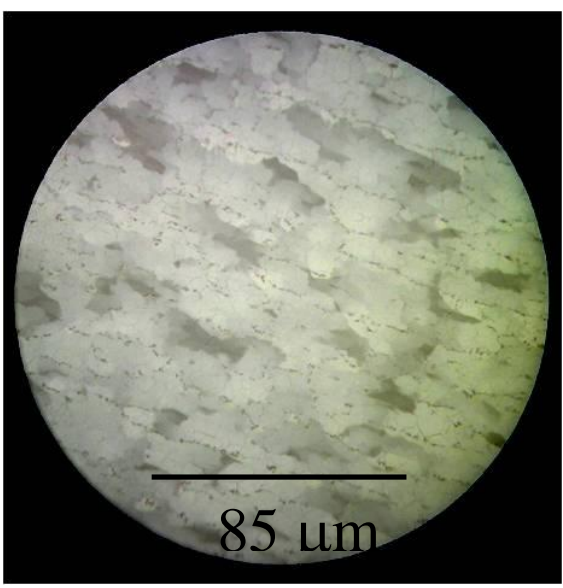

Figure 3. Nomarski micrograph of graphene on C-face $4 \mathrm{H}-\mathrm{SiC}$, same sample as in Fig. 2 (right). Note the texture across the sample.

The highest $300 \mathrm{~K}$ mobilities for Si-face growth recorded for whole substrate measurements were obtained for 1500 and $1600^{\circ} \mathrm{C}$ growths of 90 minutes duration utilizing the Ar flush; the best $300 \mathrm{~K}$ mobility and electron concentration were $620 \mathrm{~cm}^{2} \mathrm{~V}^{-1} \mathrm{~s}^{-1}, 8.8 \times 10^{12} \mathrm{~cm}^{-2}$ (AFM thickness was 1 to $3 \mathrm{~nm}$ ). This same sample had higher $77 \mathrm{~K}$ mobility values; $1560 \mathrm{~cm}^{2} \mathrm{~V}^{-1} \mathrm{~s}^{-1}$ was found for an electron concentration of $4.7 \times 10^{12} \mathrm{~cm}^{-2}$. In general the Hall cross samples prepared with the Ar flush showed the most uniform electrical properties. The best result was from a 10 $\mu \mathrm{m}$ cross on a $1600^{\circ} \mathrm{C}$ film with a thickness between 0.25 and $1 \mathrm{~nm}$ having a mobility of $860 \mathrm{~cm}^{2} \mathrm{~V}^{-1} \mathrm{~s}^{-1}$ for an electron concentration of $1.13 \times 10^{13} \mathrm{~cm}^{-2}$. These results are similar to or better than recent Hall mobility reports such as $1100 \mathrm{~cm}^{2} \mathrm{~V}^{-1} \mathrm{~s}^{-1}(\mathrm{~T}=4 \mathrm{~K})$ on a sample with an electron concentration of $3.6 \times 10^{12} \mathrm{~cm}^{-2}[1]$.

For the case of $\mathrm{C}$-face growth, the graphene morphology was much rougher and in most cases did not clearly show the regular step morphology of the starting $\mathrm{H}_{2}$ etched substrates. No obvious trends with substrate polytype were discerned. As shown in Fig. 2 (right), the graphene surface contained ridges which were not always uniform in height, ranging from 0 to $50 \mathrm{~nm}$ (AFM measurement), and some were estimated to have a thickness of $50 \mathrm{~nm}$ or less (SEM measurement). These ridges often intersected at angles that were multiples of 30 degrees but for some sample areas this was not true. It was also observed that the ridges sometimes followed underlying step edges and other times cut across steps. Removal of the graphene by the Scotch Tape method showed that the underlying sub- 
strate morphology was nearly identical to the graphene except for the ridge structure which disappeared. This underlying morphology exhibited step height variations of 1 to $15 \mathrm{~nm}$. On a larger scale the morphology, shown in the Nomarski micrograph in Fig. 3 (the same sample as in Fig. 2 (right)) was not uniform. Thickness measurements using AFM on patterned graphene ranged from about 5 to $30 \mathrm{~nm}$.

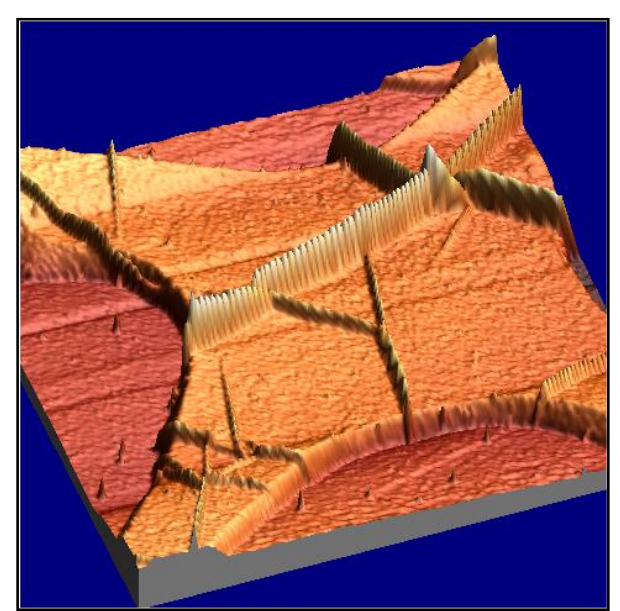

Figure 4. Atomic force microscopy map of a $2 \mu \mathrm{m}$ cross having $300 \mathrm{~K}$ hole mobility and concentration of $11,600 \mathrm{~cm}^{2} \mathrm{~V}^{-1} \mathrm{~s}^{-1}$ and $1.54 \times 10^{13} \mathrm{~cm}^{-2}$, respectively.

The best $300 \mathrm{~K}$ mobilities for $\mathrm{C}$-face growth recorded for whole substrate measurements were obtained for growths done at $1500^{\circ} \mathrm{C}$ having duration of 10 minutes using the Ar flush approach. The best $300 \mathrm{~K}$ mobility and associated electron concentration were $2160 \mathrm{~cm}^{2} \mathrm{~V}^{-}$ ${ }^{1} \mathrm{~s}^{-1}$ and $1.24 \times 10^{13} \mathrm{~cm}^{-2}$. Hall mobilities at $77 \mathrm{~K}$ were higher and the best was $3460 \mathrm{~cm}^{2} \mathrm{~V}^{-1} \mathrm{~s}^{-1}$ for an electron concentration of $2.44 \times 10^{13} \mathrm{~cm}^{-2}$. The best $300 \mathrm{~K}$ mobility value was on processed samples was $18,100 \mathrm{~cm}^{2} \mathrm{~V}^{-1} \mathrm{~s}^{-1}$ for a hole concentration of $2.1 \times 10^{12} \mathrm{~cm}^{-2}$ on a $10 \mu \mathrm{m}$ cross that was 2 to $4 \mathrm{~nm}$ thick; Figure 4 shows the AFM measured morphology of a $2 \mu \mathrm{m}$ cross in three dimensional relief (AFM thickness $11.7 \mathrm{~nm}$ ). These results are similar to or better than recent Hall mobility reports such as $9500 \mathrm{~cm}^{2} \mathrm{~V}^{-1} \mathrm{~s}^{-1}(\mathrm{~T}=180 \mathrm{mK})$ on a sample with electron concentration $3.7 \times 10^{12} \mathrm{~cm}^{-2}$ [6].

\section{Summary}

Graphene films were synthesized in a commercial $\mathrm{SiC}$ epitaxial reactor using a 2-step process that combines in-situ $\mathrm{H}_{2}$ etching of the on-axis $4 \mathrm{H}-$ or $6 \mathrm{H}-\mathrm{SiC}$ semi-insulating substrate to remove polishing damage with a $\mathrm{HV}$ processing step for graphene formation. Film morphology is described and selected electrical properties by Hall Effect measurements are presented. The electrical properties are similar to or better than recent reports and thus demonstrate that high quality graphene formation in epitaxial reactors using $\mathrm{HV}$ is a reality.

\section{Acknowledgements}

This work was supported by the Office of Naval Research. BLV and RLM-W and JLT acknowledge support from the ASEE for Postdoctoral Research Fellowships. JMM and SAK acknowledge support from the Naval Research Enterprise Intern Program.

\section{References}

[1] C.Berger, Z.Song, T.Li, X.Li, A.Y.Ogbazghi, R.Feng, Z.Dai, A.N.Marchenkov, E. H.Conrad, P.N.First, and W.A.de Heer, J. Phys. Chem. B Vol.108 (2004) p.19912.

[2] S.S.Lilov, Cryst. Res. Technol Vol.28 (1993) p.503.

[3] K.K.Lew, B.L.VanMil, R.L.Myers-Ward, R.T.Holm, C.R.Eddy, Jr., and D.K.Gaskill, Mater. Sci. Forum Vols.556-557 (2007) p.513.

[4] B.L.VanMil, K.-K.Lew, R.L.Myers-Ward, R.T.Holm, D.K.Gaskill, C.R.Eddy, Jr., L.Wang and P.Zhao, submitted J. Cryst. Growth.

[5] E. Rollings, G.-H.Gweon, S.Y.Zhou, B.S.Mun, J.L.McChesney, B.S.Hussain, A.V.Fedorov, P.N.First, W.A.de Heer, and A.Lanzara, J. Phys. Chem. Sol. Vol.7 (2006) p.2172.

[6] C.Berger, Z.Song, X.Li, X.Wu, N.Brown, D.Maud, C.Naud, W.A.de Heer Physica Status Solidi A Vol.204 (2007) p.1746. 